\title{
Femoral nerve transfers for restoring tibial nerve function: an anatomical study and clinical correlation: a report of 2 cases
}

\author{
Amy M. Moore, MD, Emily M. Krauss, MSc, MD, Rajiv P. Parikh, MD, MPHS, Michael J. Franco, MD, \\ and Thomas $\mathrm{H}$. Tung, MD
}

Division of Plastic \& Reconstructive Surgery, Washington University in St. Louis, Missouri

Sciatic nerve injuries cause debilitating functional impairment, particularly when the injury mechanism and level preclude reconstruction with primary grafting. The purpose of this study was to demonstrate the anatomical feasibility of nerve transfers from the distal femoral nerve terminal branches to the tibial nerve and to detail the successful restoration of tibial function using the described nerve transfers.

Six cadaveric legs were dissected for anatomical analysis and the development of tension-free nerve transfers from femoral nerve branches to the tibial nerve. In 2 patients with complete tibial and common peroneal nerve palsies following sciatic nerve injury, terminal branches of the femoral nerve supplying the vastus medialis and vastus lateralis muscles were transferred to the medial and lateral gastrocnemius branches of the tibial nerve. Distal sensory transfer of the saphenous nerve to the sural nerve was also performed. Patients were followed up for lower-extremity motor and sensory recovery up to 18 months postoperatively.

Consistent branching patterns and anatomical landmarks were present in all dissection specimens, allowing for reliable identification, neurolysis, and coaptation of donor femoral and saphenous nerve branches to the recipients. Clinically, the patients obtained Medical Research Council Grade 3 and $3+$ plantar flexion by 18 months postoperatively. Improved strength was accompanied by improved ambulation in both patients and by a return to competitive sports in 1 patient. Sensory recovery was demonstrated by an advancing Tinel sign in both patients.

This study illustrates the clinical success and anatomical feasibility of femoral nerve to tibial nerve transfers after proximal sciatic nerve injury.

https://thejns.org/doi/abs/10.3171/2017.5.JNS163076

KEY WORDS nerve transfer; nerve injury; lower extremity reconstruction; sciatic nerve; tibial nerve; ambulation; peripheral nerve

$\mathrm{S}$ CIATIC nerve injuries result in functional disability secondary to lower-extremity motor impairment, altered gait, and loss of foot sensation. In very proximal lesions, the reconstructive challenges are unique because the proximal nerve stump can be inaccessible or reconstruction can require long nerve grafts..$^{12,14}$, ${ }^{15,19}$ Functional recovery using long nerve grafts has been disappointing because of the degeneration of distal motor endplates before muscle reinnervation can occur and/ or the lack of sufficient graft material for reconstruction. ${ }^{4}$ Traditional management has consisted of ankle-foot orthoses (AFOs), tendon or muscle transfers, or ankle ar- throdesis. ${ }^{4,5,12,14,17,21,22,25}$ Reconstructive priority is given to the tibial nerve to restore protective foot sensation and plantar flexion strength for push off in the stance-to-swing phase of walking. ${ }^{17,19}$

Nerve transfer coapts a healthy neighboring expendable donor nerve or fascicle to a denervated recipient nerve to restore target muscle function, minimizing the distance and time for regeneration. ${ }^{6,27,28}$ Nerve transfers in the lower extremity have included the femoral and obturator nerves for thigh or hip function, tibial to peroneal nerve transfers for foot drop, and sensory nerve transfers for plantar foot sensation. , $7-9,16,20,23,26,28$ In the case of high sciatic nerve le- 
sions, both tibial and peroneal nerve function are lost and reported available donor nerves are located proximally in the thigh. The transfer of obturator nerve branches to motor branches of the tibial nerve has been reported but requires long nerve grafts more than $20 \mathrm{~cm}$ in length. ${ }^{32} \mathrm{In}$ the present report, we describe the successful restoration of plantar flexion through a novel motor nerve transfer using femoral nerve terminal branches to the vastus medialis and lateralis muscles in the distal thigh to the medial and lateral gastrocnemius branches of the tibial nerve. We describe a staged sensory nerve transfer using a saphenous to tibial nerve transfer with an intermediary sural nerve transfer to restore protective foot sensation.

Approval from the institutional review board was not required for this study.

\section{Cadaveric Dissection}

Anatomy of the femoral nerve terminal motor divisions to the vastus medialis and lateralis muscles and the tibial and common peroneal divisions of the sciatic nerve was dissected in 6 cadaveric limbs. The sural nerve and branches of the tibial nerve to the medial and lateral head of the gastrocnemius muscle were neurolyzed proximally to determine whether direct coaptation to terminal femoral nerve divisions was feasible.

Donor and recipient nerve samples were taken from 2 cadaveric limbs for histological analysis. The nerves were fixed in 3\% glutaraldehyde solution (Polysciences Inc.) in $0.1 \mathrm{M}$ phosphate buffer ( $\mathrm{pH}$ 7.2) at $4^{\circ} \mathrm{C}$ prior to sectioning and histomorphological analysis. We then postfixed the tissues with $1 \%$ osmium tetroxide and serially dehydrated them in ethanol. Specimens were embedded in Araldite 502 (Polysciences Inc.) and sectioned into 1- $\mu$ m-thick cross sections using an LKB Broma 8800 Ultratome III microtome (LKB Instruments). We stained the sections with $1 \%$ toluidine blue and evaluated them via light microscopy. Microscopic images were analyzed with an automated digital image analysis system linked to histomorphometry software to quantify the total nerve fiber count. ${ }^{10}$

The nerves to the vastus medialis and lateralis muscles were dissected in the thigh. Terminal nerve branches to the vastus lateralis muscle reside adjacent to the lateral femoral circumflex vessels, and the branching pattern was consistent. Proximal subdivisions were present in both the vastus medialis and lateralis nerve branches, supplying the proximal and distal segments of each muscle segmentally. These branches then divided into several terminal branches ( $>1 \mathrm{~mm}$ in diameter), on average 7 in the vastus medialis nerve and 6 in the vastus lateralis nerve (Figs. 1 and 2 and Table 1). The most distal branches of the femoral nerve to the vastus medialis branch were found an average of $10.7 \mathrm{~cm}(\mathrm{SD} 2.1 \mathrm{~cm})$ proximal to the patella, on a line from the superomedial aspect of the patella to the pubic symphysis (Fig. 3). The most distal branches of the vastus lateralis were found an average $15.5 \mathrm{~cm}$ (SD 3.5 $\mathrm{cm}$ ) proximal to the patella, on a line from the superolateral aspect of the patella to the anterior superior iliac spine. These motor branches cannot be mobilized since doing so would require unnecessary sacrifice of more proximal

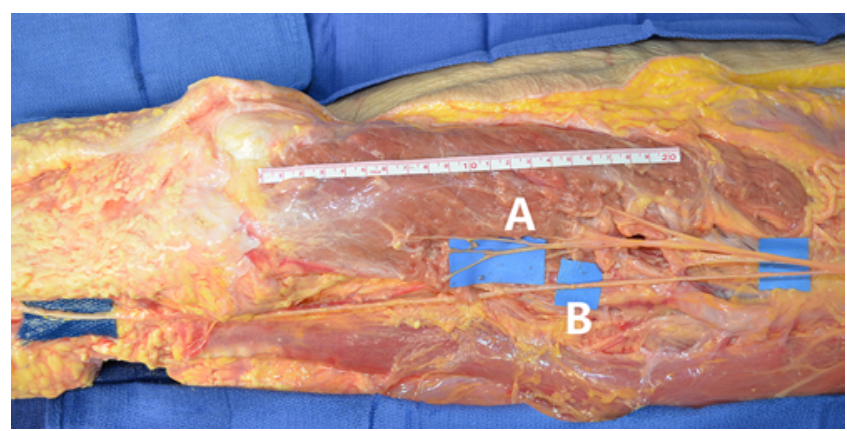

FIG. 1. Cadaver dissection of medial thigh demonstrating femoral nerve branches $(A)$ to the vastus medialis nerve branch and saphenous nerve (B). Copyright Thomas Tung. Published with permission. Figure is available in color online only.

motor branches, but they are exposed to allow coaptation to the target motor nerve branches, which are transposed from the posterior to the anterior leg. The saphenous nerve was identified approximately $3 \mathrm{~cm}$ medial to the distal branches of the vastus medialis nerve.

Recipient nerve branches of the tibial and sural nerves were identified, and proximal neurolysis of the medial and lateral gastrocnemius branches and the sural nerve was performed. The medial gastrocnemius branch was easily located arising from the deep medial surface of the tibial nerve. Sural nerve fascicles were located superficial to the motor fascicles. Topographically, the medial gastrocnemius fascicles are in the medial half of the tibial nerve, with sural nerve fascicles located superficial and midline and the lateral gastrocnemius fascicles located laterally. Proximal neurolysis mobilized the medial and lateral gastrocnemius branches and the sural nerve up to $8.4 \mathrm{~cm}(\mathrm{SD} 1.2 \mathrm{~cm}), 8.2 \mathrm{~cm}(\mathrm{SD} 2.7 \mathrm{~cm})$, and $11.4 \mathrm{~cm}$ $(\mathrm{SD} 3.2 \mathrm{~cm}$ ) proximal to the popliteal crease, respectively (Fig. 4). These distances correspond approximately with the transferrable lengths of the motor branches since the gastrocnemius muscles originate above the knee from the femoral condyles.

Histomorphometric analysis demonstrated the nerve fiber counts of the medial and lateral gastrocnemius and

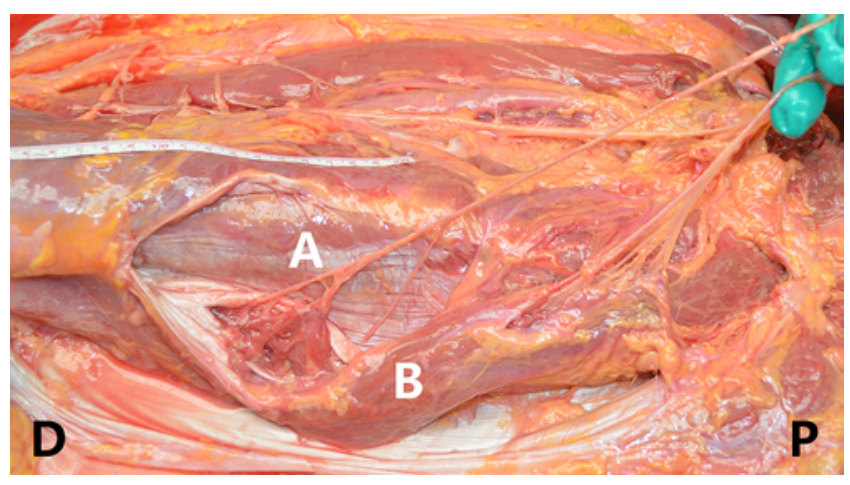

FIG. 2. Cadaver dissection of lateral thigh demonstrating femoral nerve branches $(A)$ to the vastus lateralis muscle $(B) . D=\operatorname{distal} ; P=$ proximal. Copyright Thomas Tung. Published with permission. Figure is available in color online only. 
TABLE 1. Donor femoral nerve terminal branches and anatomical landmarks in 6 cadaveric dissections

\begin{tabular}{|c|c|c|c|}
\hline $\begin{array}{l}\text { Donor } \\
\text { Nerve }\end{array}$ & $\begin{array}{l}\text { Mean No. } \\
\text { of Terminal } \\
\text { Branches } \\
>1 \mathrm{~mm} \\
\text { diameter }\end{array}$ & $\begin{array}{l}\text { Anatomical } \\
\text { Landmark }\end{array}$ & $\begin{array}{c}\text { Mean Distance } \\
\text { of } \\
\text { Distal Branch } \\
\text { to Patella }\end{array}$ \\
\hline $\begin{array}{l}\text { Femoral nerve } \\
\text { to vastus } \\
\text { medialis } \\
\text { nerve branch }\end{array}$ & 7 & $\begin{array}{l}\text { Along a line from } \\
\text { pubic symphysis } \\
\text { to superomedial } \\
\text { aspect of patella }\end{array}$ & $\begin{array}{l}10.7 \mathrm{~cm} \text { (SD } 2.1 \\
\mathrm{~cm} \text { ) proximal to } \\
\text { patella }\end{array}$ \\
\hline $\begin{array}{l}\text { Femoral nerve } \\
\text { to vastus } \\
\text { lateralis } \\
\text { nerve branch }\end{array}$ & 6 & $\begin{array}{l}\text { Along a line } \\
\text { from ASIS to } \\
\text { superolat aspect } \\
\text { of patella }\end{array}$ & $\begin{array}{l}15.5 \mathrm{~cm} \text { (SD } 3.5 \\
\mathrm{~cm} \text { ) proximal to } \\
\text { patella }\end{array}$ \\
\hline $\begin{array}{l}\text { Saphenous } \\
\text { nerve }\end{array}$ & NA & & $\begin{array}{l}3 \mathrm{~cm} \text { medial to } \\
\text { distal branches } \\
\text { of femoral } \\
\text { nerve to vastus } \\
\text { medialis }\end{array}$ \\
\hline
\end{tabular}

ASIS = anterior superior iliac spine; NA = not applicable.

vastus medialis and lateralis motor nerves (Table 2). As expected, the terminal branches of the vastus medialis and lateralis contained significantly fewer than the motor branches to the medial and lateral gastrocnemius muscles but enough to reinnervate the target muscles and provide functionally significant contractile force. Physically, the size match is very reasonable, which facilitates the technical coaptation. The diameter of the medial and lateral gastrocnemius motor branches is approximately $1.5-2 \mathrm{~mm}$, depending on the level. The distal vastus medialis branch has a similar diameter, while the vastus lateralis branch is smaller and an additional branch(es) may be taken to improve the donor axon load and size match.

\section{Surgical Technique}

With the patient prone, a curvilinear incision was made along the popliteal fossa to expose the sciatic nerve proximally and the tibial and common peroneal nerves distally (Fig. 5). The tibial nerve was found medial to the peroneal nerve in the popliteal fossa. Tibial nerve branches to the medial and lateral heads of the gastrocnemius muscle were identified and neurolyzed proximally to maximize their length for transfer. The sural nerve was located in a position between and superficial to the gastrocnemius branches. The medial gastrocnemius branch and sural nerve were divided proximally and tunneled through the medial soft tissue for later coaptation to femoral nerve branches of the vastus medialis and saphenous nerve, respectively (Fig. 6A and B). The lateral gastrocnemius branch was divided proximally and passed through a lateral soft tissue tunnel.

The patient was turned supine, and an anterolateral thigh incision was made on the medial border of the vastus lateralis muscle, exposing its obliquely oriented fibers (Fig. 5). A plane between the rectus femoris and vastus

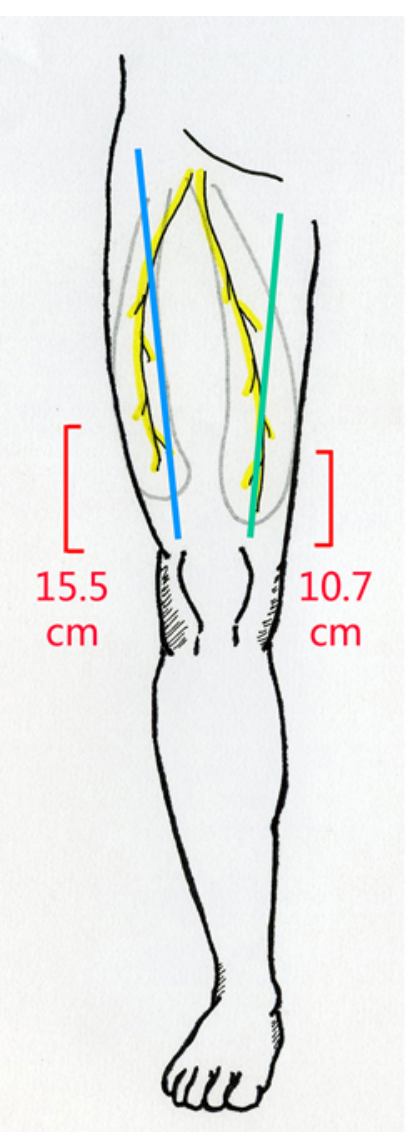

FIG. 3. The anatomical landmarks for the femoral nerve branches to the vastus medialis and lateralis branches. The vastus medialis branch is located along a line (green) from the pubic symphysis to the superomedial patella. Terminal branches are identified $10.7 \mathrm{~cm}(S D 2.1 \mathrm{~cm})$ proximal to the patella. The femoral nerve branches to the vastus lateralis branches are seen along a line (blue) from the anterior superior iliac spine to the superolateral patella. Terminal branches are identified $15.5 \mathrm{~cm}$ (SD 3.5 $\mathrm{cm}$ ) proximal to the patella. Copyright Thomas Tung. Published with permission. Figure is available in color online only.

lateralis muscles was dissected. Multiple femoral nerve branches were identified residing with the lateral femoral circumflex vessels and entering the vastus lateralis muscle segmentally. Terminal nerve branches were neurolyzed proximally for maximal transfer length (Fig. 6C). The branch to the lateral gastrocnemius was identified in the lateral soft-tissue tunnel and transposed anteriorly for tension-free coaptation with the donor (Fig. 6D). An anteromedial incision was made on the posterior border of the vastus medialis muscle just proximal to the medial femoral condyle (Fig. 5). Incising through the posterior fascia of the muscle, the saphenous branch of the femoral nerve was identified and neurolyzed distally. Dissection proceeded beneath the vastus medialis muscle and its posterior fascia, and we identified multiple femoral motor nerve branches entering the undersurface of the muscle. Approximately 2-3 distal terminal branches greater than $1 \mathrm{~mm}$ in diameter and with an appropriate size match to the recipient branch were selected as the donor nerve, neurolyzed, divided distally, and transposed posteriorly be- 


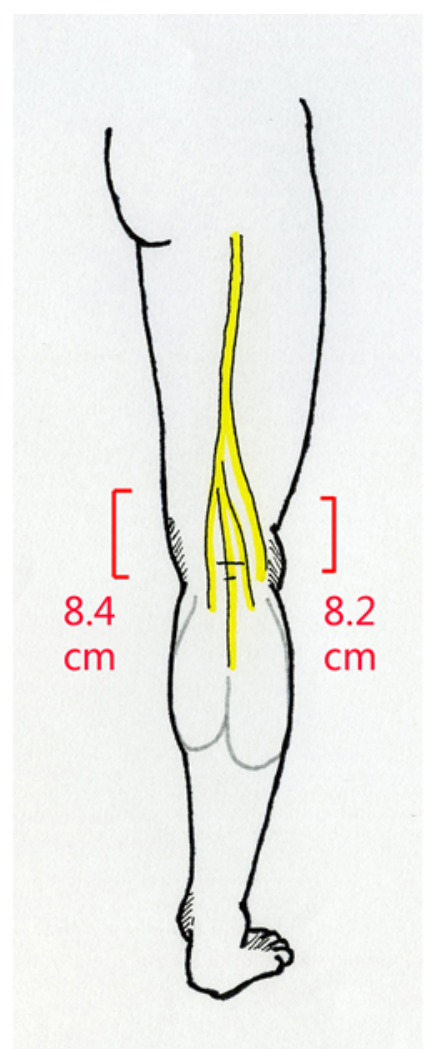

FIG. 4. The tibial nerve branches to the medial and lateral gastrocnemius muscle can be neurolyzed $8.4 \mathrm{~cm}(\mathrm{SD} 2.1 \mathrm{~cm})$ and $8.2 \mathrm{~cm}(\mathrm{SD} 2.7$ $\mathrm{cm})$ proximal to the popliteal crease, respectively. The sural nerve can be neurolyzed $11.4 \mathrm{~cm}(\mathrm{SD} 3.2 \mathrm{~cm})$ proximal to the popliteal crease. Copyright Thomas Tung. Published with permission. Figure is available in color online only.

tween the vastus medialis and gracilis muscles to the soft tissue tunnel containing the sural nerve and the branch to the medial gastrocnemius (Fig. 6C and D). For each transfer, a tension-free nerve coaptation was performed under the operating microscope using 9-0 nylon microsutures and fibrin glue sealant.

TABLE 2. Histological nerve fiber counts for terminal branches of the donor nerve, and nerve fiber counts of complete cross section of recipient nerve at the level of transfer in 2 cadaveric dissections

\begin{tabular}{lc}
\hline Nerve Sectioned for Histological Analysis & Total Fiber Count \\
\hline Donor nerve terminal branches & \\
\hline Vastus medialis nerve (donor) & 1019 \\
\hline Vastus lateralis nerve (donor) & 455 \\
\hline Saphenous nerve (sensory donor) & 3782 \\
\hline Recipient nerve complete cross section & \\
\hline Medial gastrocnemius nerve (recipient) & 4359 \\
\hline Lateral gastrocnemius nerve (recipient) & 2801 \\
\hline Sural nerve (sensory recipient) & 1935 \\
\hline
\end{tabular}

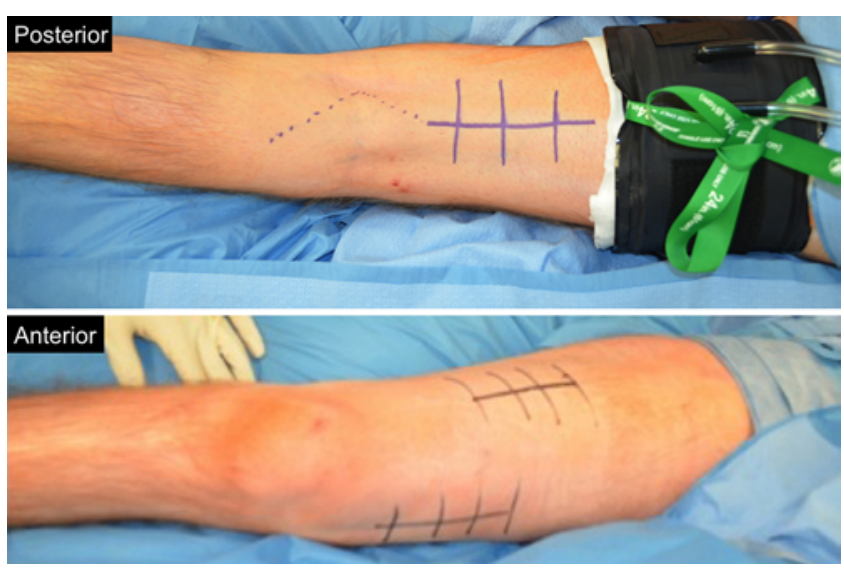

FIG. 5. Upper: The patient is first positioned prone, with a surgical incision in the distal thigh allowing for possible extension across the popliteal crease for tibial nerve branch identification and neurolysis. Lower: Two anterior incisions, medial and lateral, are used to isolate the distal femoral nerve branches to the vastus medialis branches, saphenous nerve, and vastus lateralis branches, respectively. Figure is available in color online only.

\section{Case Reports \\ Case 1 \\ History and Examination}

A 13-year-old male presented with lumbosacral plexopathy and left sciatic nerve palsy 6 months after a left hip dislocation sustained in a motorcycle accident. Paralysis of his lower leg and foot with loss of sensation was reported at the time of injury. Magnetic resonance imaging 4 months after injury demonstrated unilateral L5-S1 nerve root avulsions with enlargement and edematous changes to the left sciatic nerve and lumbosacral plexus. The patient's chief complaint was inability to ambulate effectively. Physical examination showed marked diffuse atrophy of his lower leg with flaccid paralysis below the knee, and Medical Research Council (MRC) Grade 0 ankle dorsiflexion and plantar flexion (Video 1).

VIDEO 1. Case 1. Video clip of preoperative gait illustrating a flail limb below the left knee. Copyright Thomas Tung. Published with permission. Click here to view.

Sensation was absent in his lateral lower leg and foot. Electromyography (EMG) examination demonstrated 3+ fibrillations and positive sharp waves in the gluteus medius, gluteus maximus, biceps femoris, gastrocnemius, and tibialis anterior muscles consistent with proximal sciatic nerve injury. Motor unit action potentials were seen only in the gluteus maximus muscle. Quadriceps and adductor muscle function were intact and normal on EMG.

The patient's goals were to ambulate effectively and to participate in recreational activities and sports. To achieve this, he would require the restoration of plantar flexion and protective foot sensation. Root avulsion precluded proximal reconstruction. Thus, motor nerve transfer using the terminal branches of the nerve to the vastus medialis muscle to the medial gastrocnemius nerve was performed, 


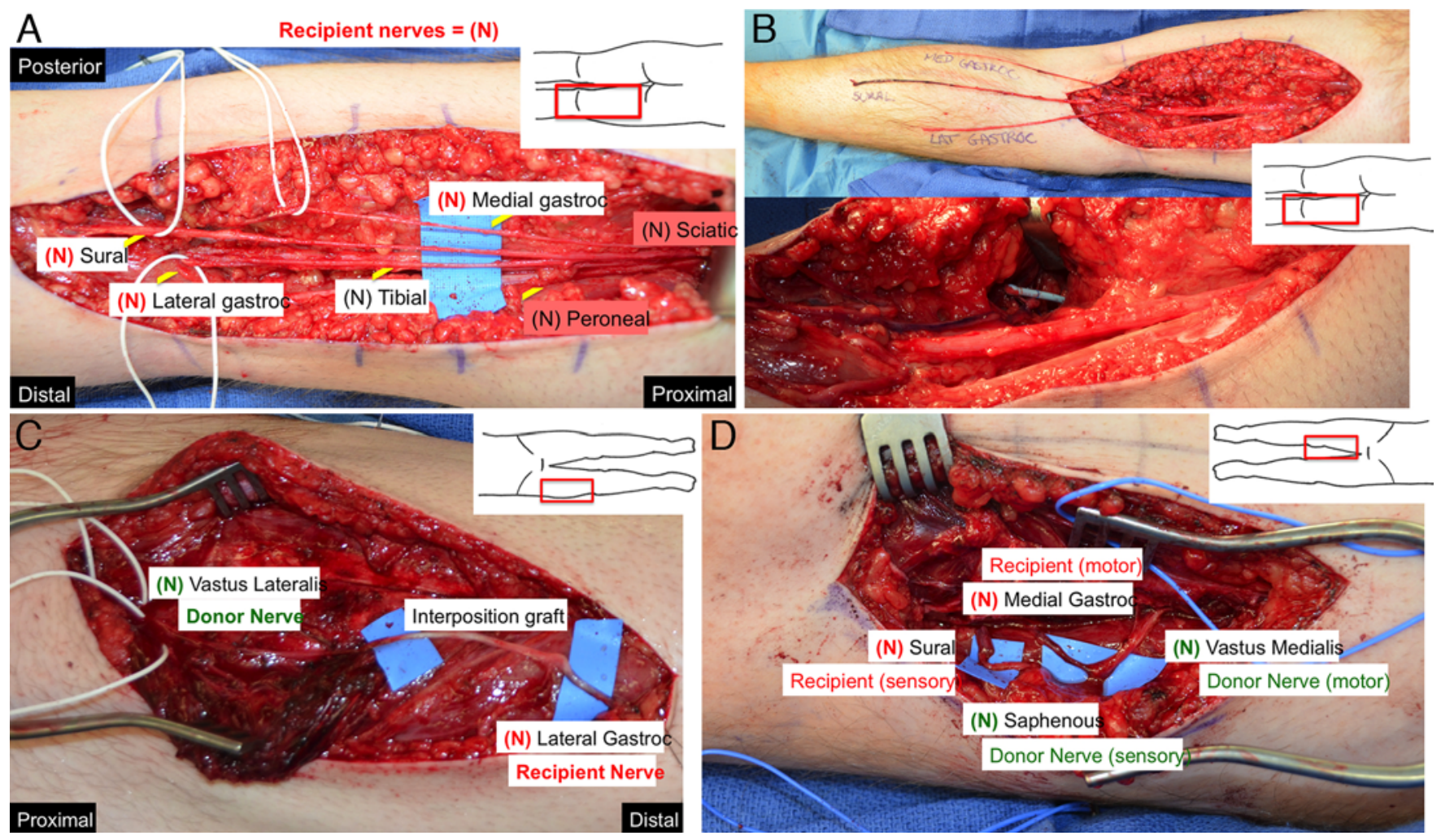

FIG. 6. Case 2. A: Intraoperative dissection, and neurolysis of right tibial nerve branches to the medial gastrocnemius, sural, and lateral gastrocnemius nerves. B: Note the length of proximal neurolysis and division of the recipient tibial nerve branches (upper), allowing for end-to-end coaptation of the vastus medialis and sensory nerve transfers. Soft tissue tunnels are created to pass the nerves to the anterior leg (lower). C: After a lateral incision, the terminal branches to the vastus lateralis nerve are identified and coapted to a $7-\mathrm{cm}$ interpositional nerve graft (from the contralateral sural nerve) to the lateral gastrocnemius nerve. D: Through a medial incision, the terminal branches to the vastus medialis nerve and the saphenous nerve are coapted end-to-end to the nerve to the medial gastrocnemius and sural nerves, respectively. Gastroc = gastrocnemius. Figure is available in color online only.

as was a first-stage sensory nerve transfer of the saphenous to sural nerve, which will be later transferred to the distal tibial nerve at the ankle.

\section{Operation}

The nerve transfers performed included the vastus medialis nerve to the medial gastrocnemius nerve and sen- sory transfer from the saphenous to the sural nerve (Table 3 ). As our first experience with this procedure, the vastus medialis nerve was the only chosen donor for motor transfer. Both transfers required an 8-cm ipsilateral superficial peroneal nerve graft.

For the second-stage sensory nerve transfer, the distal sensory tibial nerve was dissected at the medial ankle and

TABLE 3. Planned nerve transfers to restore tibial nerve function in 2 patients

\begin{tabular}{cll}
\hline Donor & \multicolumn{1}{c}{ Transfer Technique } & Recipient \\
\hline Case 1: Stage 1 & & \\
\hline Vastus medialis nerve & 8-cm interpositional nerve graft & Medial gastrocnemius nerve \\
\hline Saphenous nerve & 8-cm interpositional nerve graft & Sural nerve \\
\hline Case 1: Stage 2 16 mos) & & \\
\hline Distal sural nerve & Direct coaptation & Tibial nerve at medial ankle \\
\hline Case 2: Stage 1 & & Lateral gastrocnemius nerve \\
\hline Vastus lateralis nerve & 7-cm interpositional nerve graft & Medial gastrocnemius nerve \\
\hline Vastus medialis nerve & Direct coaptation & Sural nerve \\
\hline Saphenous nerve & Direct coaptation & \\
\hline Case 2: Stage 2 (planned) & & Tibial nerve at medial ankle \\
\hline Distal sural nerve & Direct coaptation &
\end{tabular}


TABLE 4. Injury features and results of terminal femoral nerve branch transfers to tibial nerve gastrocnemius branches

\begin{tabular}{|c|c|c|}
\hline Parameter & Case 1 & Case 2 \\
\hline Mechanism & $\begin{array}{r}\text { Traumatic hip } \\
\text { dislocation }\end{array}$ & $\begin{array}{l}\text { Gluteal compartment } \\
\text { syndrome }\end{array}$ \\
\hline Nerve injury & $\begin{array}{l}\text { Lt lumbosacral } \\
\text { plexopathy, no re- } \\
\text { covery in sciatic } \\
\text { nerve }\end{array}$ & $\begin{array}{l}\text { Proximal debridement } \\
\text { of rt sciatic nerve } \\
\text { along entire course } \\
\text { w/in gluteal muscles }\end{array}$ \\
\hline $\begin{array}{l}\text { Time to op intervention } \\
\text { after injury in mos }\end{array}$ & 6 & 4 \\
\hline $\begin{array}{l}\text { First reinnervation after } \\
\text { nerve transfer in mos }\end{array}$ & 6 & 4 \\
\hline Final follow-up in yrs & 3 & 2 \\
\hline $\begin{array}{l}\text { Final quadriceps } \\
\text { strength (donor) }\end{array}$ & $\begin{array}{l}\text { MRC Grade 5; } \\
\text { microFET2 } 87 \text { lbs } \\
\text { (contralat } 78 \text { lbs) }\end{array}$ & $\begin{array}{l}\text { MRC Grade 5; } \\
\text { microFET2 } 104 \text { lbs } \\
\text { (contralat } 84 \mathrm{lbs} \text { ) }\end{array}$ \\
\hline $\begin{array}{l}\text { Final gastrocnemius } \\
\text { strength (recipient) }\end{array}$ & $\begin{array}{l}\text { MRC Grade 3+; } \\
\text { microFET2 } 15 \mathrm{lbs} \\
\text { (contralat } 63 \mathrm{lbs} \text { ) }\end{array}$ & $\begin{array}{l}\text { MRC Grade 3; } \\
\text { microFET2 } 31 \mathrm{lbs} \\
\text { (contralat } 110 \mathrm{lbs} \text { ) }\end{array}$ \\
\hline
\end{tabular}

the tarsal tunnel was decompressed. The sural nerve and its distal branches were mobilized posterior to the lateral malleolus, divided distally, and tunneled subcutaneously to the recipient tibial nerve at the medial ankle for a direct end-to-end transfer.

\section{Postoperative Course and Functional Outcome}

At 1 month postoperatively, the patient started dedicated motor and sensory reeducation. Strategies for lowerextremity reeducation were based on the donor activation focused rehabilitation approach (DAFRA) protocols established for the upper extremity. ${ }^{11}$ This rehabilitation model is designed to reinforce the new neural pathways altered by nerve transfer to optimize functional outcome. The patient was followed up postoperatively at 1- to 3-month intervals, and guided therapy was initiated and advanced at each visit.

The patient experienced increasing gastrocnemius strength by 6 months postoperatively (Table 4). Approximately 16 months after his initial surgery, he underwent completion of the staged sensory nerve transfers with a sural to distal tibial nerve transfer. At the 18 -month postoperative visit, he had improved calf bulk and MRC Grade 3+ gastrocnemius function with active plantar flexion of $60^{\circ}$.

At the final follow-up at 3 years, his force evaluating and testing (FET; microFET2, Hoggan Health Industries) dynamometer peak force for plantar flexion was $15 \mathrm{lbs}$ (63 lbs on the contralateral side). His quadriceps peak force was $87 \mathrm{lbs}$ (contralateral $78 \mathrm{lbs}$ ), and there was no donor morbidity. He was able to resume all of his previous activities, including basketball and running with the use of an AFO for persistent foot drop (Fig. 7 and Videos 2-4).

VIDEO 2. Case 1. Video clip obtained at the 3 -year follow-up, illustrating improved stability and push-off strength but persistent foot drop requiring a dorsiflexion assist splint (peroneal nerve not

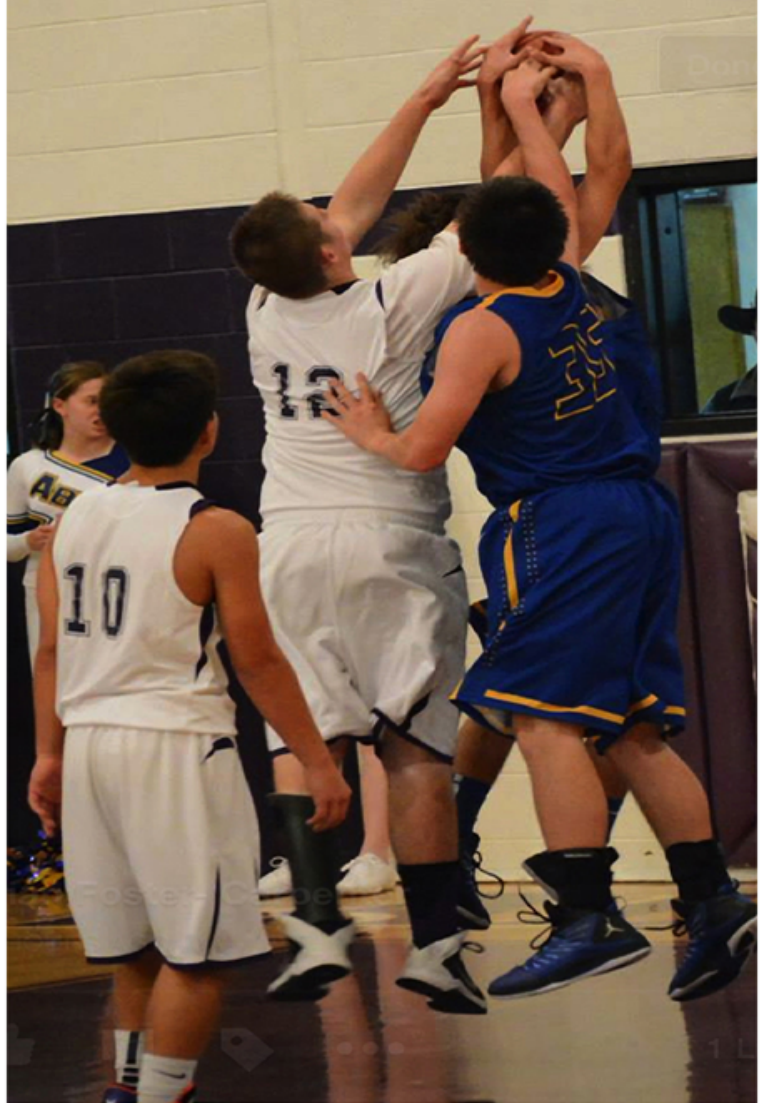

FIG. 7. Case 1. The patient playing basketball while using an AFO. Figure is available in color online only.

reconstructed). Copyright Thomas Tung. Published with permission. Click here to view.

VIDEO 3. Case 1. Video clip obtained at the 3-year follow-up, showing better speed and flow of ambulation. Copyright Thomas Tung. Published with permission. Click here to view.

VIDEO 4. Case 1. Video clip obtained at the 3-year follow-up, illustrating the ability to run with the use of an AFO to correct foot drop. Copyright Thomas Tung. Published with permission. Click here to view.

Tinel's sign was present over his tibial nerve distribution on the plantar surface of his foot, and he reported improved contact surface sensation to his foot. He maintained MRC Grade 3+ plantar flexion strength. For dorsiflexion, he underwent a free-functional gracilis muscle transfer powered by a banked nerve graft to the anterior obturator branch on the injured limb and is in the early recovery and rehabilitation phase.

\section{Case 2}

History and Examination

A 26-year-old male presented with right sciatic nerve palsy 4 months after suffering compartment syndrome and ischemia-reperfusion injury to his right gluteal region. Initial gluteal fasciotomies and serial muscle debridements were performed at an outside hospital. His chief complaint 


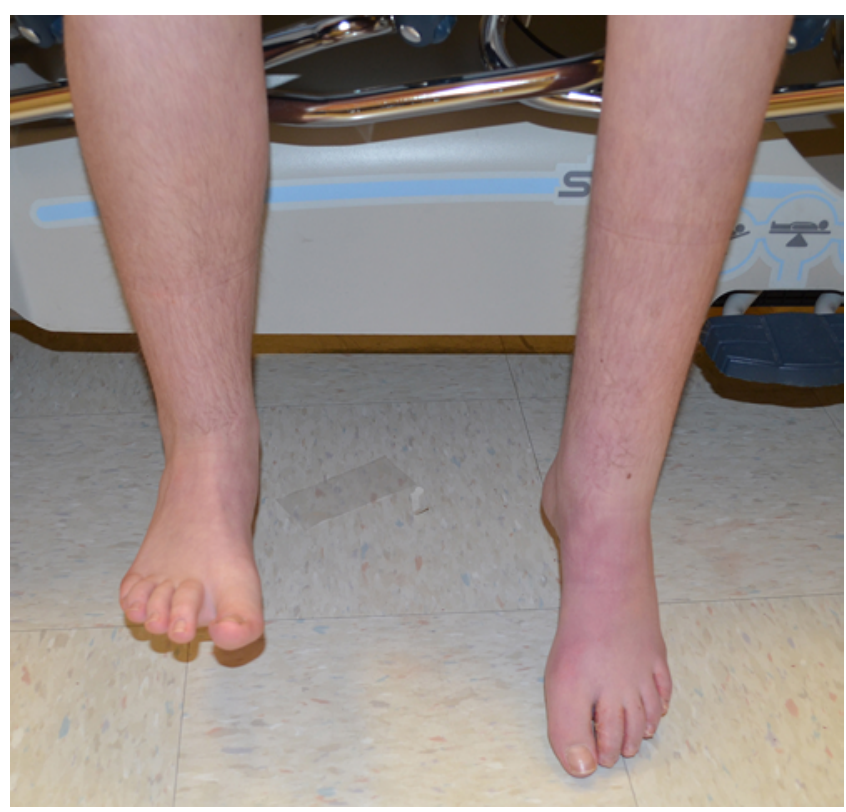

FIG. 8. Case 2. Photograph obtained 4 months postinjury with resected right proximal sciatic nerve illustrating characteristic foot drop and atrophy of the leg below the knee. Figure is available in color online only.

was an impaired ability to ambulate. Physical examination demonstrated diffuse lower leg atrophy, absent plantar and dorsiflexion, and absent plantar foot sensation, although he did have some feeling in his medial instep (Fig. 8 and Video 5).

VIDEO 5. Case 2. Video clip of preoperative gait illustrating a flail limb below the left knee and circumduction to clear the foot.

The gait is slow and appears unstable. Copyright Thomas Tung.

Published with permission. Click here to view.

Quadriceps and adductor muscle motor function were intact. Electromyography at 3 months demonstrated greater than 2+ fibrillations and positive sharp waves indicating denervation of tibial- and peroneal-innervated muscles and no motor unit potentials in the tibialis anterior or gastrocnemius muscles.

The ischemic etiology with large soft-tissue destruction, proximal location, and anticipated scarring predicted a poor outcome from nerve grafting. ${ }^{19}$ The goals of reconstruction were restoration of plantar flexion to improve push-off strength for ambulation and plantar foot sensation. We chose to do a double motor transfer using terminal branches from the vastus lateralis and medialis nerves to the lateral and medial gastrocnemius nerves, respectively. Staged sensory nerve transfers were done as in the first patient.

\section{Operation}

Given our experience in Case 1, further neurolysis of recipient gastrocnemius motor branches was performed in the patient in Case 2 for additional reach to the donor nerves anteriorly. To reconstruct for more power, both the vastus medialis to medial gastrocnemius and the vastus lateralis to lateral gastrocnemius nerve transfers were performed (Table 3). Transfer of the terminal branches of the

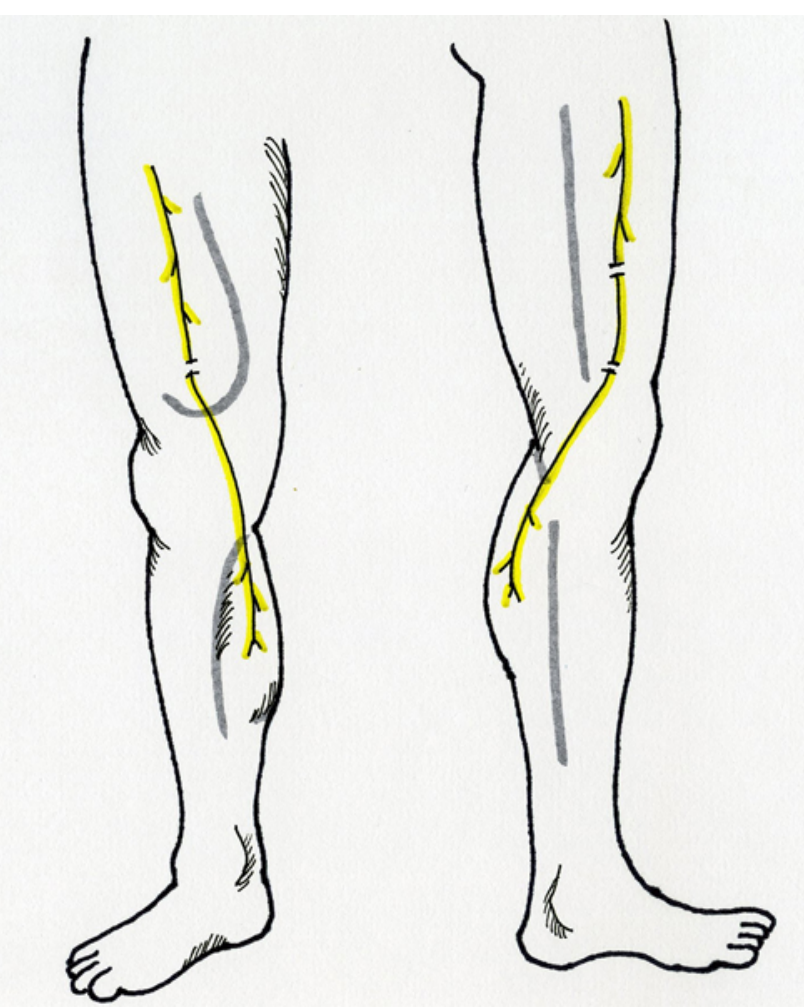

FIG. 9. Case 2. Illustration of motor transfers: Terminal branch of the vastus medialis directly to the medial gastrocnemius branch (left) and terminal branch of the vastus lateralis to lateral gastrocnemius branch with a 7-cm graft (right). Copyright Thomas Tung. Published with permission. Figure is available in color online only.

vastus medialis to medial gastrocnemius nerve and the saphenous to sural nerve were performed directly without grafts. The vastus lateralis transfer to the lateral gastrocnemius nerve required a $7-\mathrm{cm}$ nerve graft for a tension-free coaptation through the full range of knee motion (Figs. 6C and $\mathrm{D}$ and 9$)$.

\section{Postoperative Course and Functional Outcome}

At 1 month postoperatively, the patient started dedicated motor and sensory reeducation. Strategies for lower extremity reeducation were based on the DAFRA protocols established for the upper extremity. ${ }^{11}$ The patient was followed up at 1- to 3-month intervals postoperatively, and guided therapy was initiated and advanced at each visit.

In this patient, the first sign of gastrocnemius innervation was reported by 4 months postoperatively (Table 4). At his 9-month postoperative visit, he demonstrated improved calf bulk and MRC Grade 3- gastrocnemius function. He continued to improve to MRC Grade 3 at the 2-year follow-up (Fig. 10). Quadriceps muscle strength (MRC 5) was maintained without deficit. His FET dynamometer peak force for plantar flexion was $31 \mathrm{lbs}$ (contralateral $110 \mathrm{lbs}$ ). His quadriceps peak force was $104 \mathrm{lbs}$ (contralateral $86 \mathrm{lbs}$ ). He reported marked improvement in his ability to ambulate (Videos 6 and 7).

VIDEO 6. Case 2. Video clip obtained at the 2-year follow-up, demonstrating the restoration of active plantar flexion with resistance 

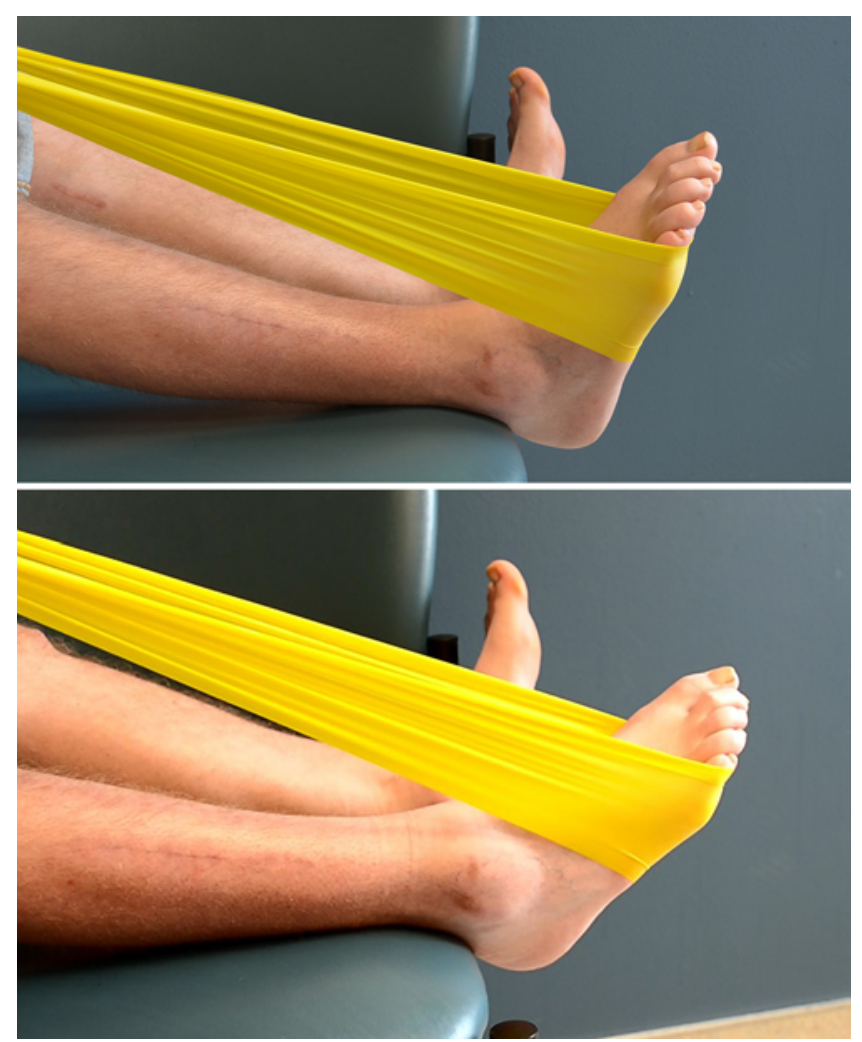

FIG. 10. Case 2. Images obtained at the 2-year follow-up, demonstrating restoration of active plantar flexion against a tension band. Figure is available in color online only.

against a tension band. Copyright Thomas Tung. Published with permission. Click here to view.

VIDEO 7. Case 2. Video clip obtained at the 2-year follow-up, illustrating improved stability, push-off strength, and speed of walking after femoral to tibial nerve transfers. Copyright Thomas Tung. Published with permission. Click here to view.

At 18 months, the patient had improved lower-leg sensation with Tinel's sign over his sural nerve distribution distally. Sensation to the medial instep of his foot remained unchanged postoperatively due to the multiple sensory branches from the femoral nerve including the saphenous nerve. He has declined to undergo the second-stage sensory transfer to the posterior tibial nerve.

\section{Discussion}

Motor function after nerve injury is dependent on the time to reinnervation and the number of motor axons reinnervating the target muscle. Nerve transfers bypass the zone of injury and minimize the need for long nerve grafts. ${ }^{28}$ In complex limb trauma, nerve transfers are particularly advantageous when root avulsion injuries and high levels of injury preclude access to the proximal nerve stump or require a prohibitively long distance for nerve regeneration. In the lower extremity, the use of nerve transfers has primarily focused on treating peroneal nerve injury. $2,8,9,20$

Walking is a rhythmic cyclical pattern characterized by time- and phase-specific muscle activation. ${ }^{31}$ Tibial nerve function is critical to ambulation because it provides protective foot sensation and plantar flexion for normal push off in the stance-to-swing phase of walking. ${ }^{17,19}$ Gait analysis has illustrated that the tibial nerve activates gastrocnemius and soleus muscles to stabilize the ankle during the stance phase of walking and provides explosive force to propel the body forward at toe off. ${ }^{31}$ Without sciatic nerve function, lower-extremity stability is impaired during the stance phase, and there is significant loss of propulsion strength due to loss of plantar flexion.

In select patients with sciatic nerve injury and no sign of motor recovery after 4-6 months, femoral to tibial nerve transfers can restore propulsion strength by reinnervating plantar flexors closer to the motor endplate and avoiding the original zone of injury. Our outcomes demonstrate that the terminal branches of the femoral nerve have sufficient axons to reinnervate the gastrocnemius muscles. The patients were also able to adjust their neural strategy to coordinate gastrocnemius muscle activation by using quadriceps muscle innervation while walking, highlighting the adaptability of biarticular muscles reported in early gait studies..$^{30}$ One limitation of the technique in our first patient included the need for interpositional nerve grafts, increasing the number of coaptations the regenerating nerve had to traverse. ${ }^{24}$ In the brachial plexus and facial reanimation literature, functional recovery is variable with the use of nerve grafts in free functional muscle transfer. ${ }^{18,29}$ Our experience with Case 1 encouraged us to perform a more proximal neurolysis of the recipient tibial nerve in Case 2 to increase the length of nerve for transfer and to perform direct coaptation of the vastus medialis to medial gastrocnemius motor branches and sensory nerve transfers. We noted a better functional outcome in the second patient and attribute it to both the direct transfer of the vastus medialis to medial gastrocnemius motor branches without the need for a graft, and to the additional transfer using the vastus lateralis nerve to innervate the lateral gastrocnemius muscle. As in brachial plexus injuries and free functional muscle transfers, superior function is anticipated if nerve grafts can be avoided and the regenerating axons only have to traverse one suture line.

Rigorous and coordinated rehabilitation with a specialist optimizes the success of nerve transfers. Compared with that for an upper extremity, functional rehabilitation of a lower extremity is complicated by the coordination and repetition required for walking. As in upper-extremity reconstruction, the use of motor donors that provide an action synergistic to the target muscle, rather than antagonistic, will provide a better functional outcome. Other successful donor-recipient pairs may not be directly synergistic, but control complementary functions, such as the tenodesis effect of wrist extension and finger flexion.

In lower-extremity injuries, such as sciatic nerve palsy, the choice of motor donors is much more limited by availability, synergy, and proximity. The terminal motor branches of the vasti muscles are the only available donors that can be used for transfer to the lower leg muscles without a long nerve graft. Fortunately, they also provide a complementary function to the plantar flexors in gait kinetics. In midstance after flat foot, the glutei, vasti, 


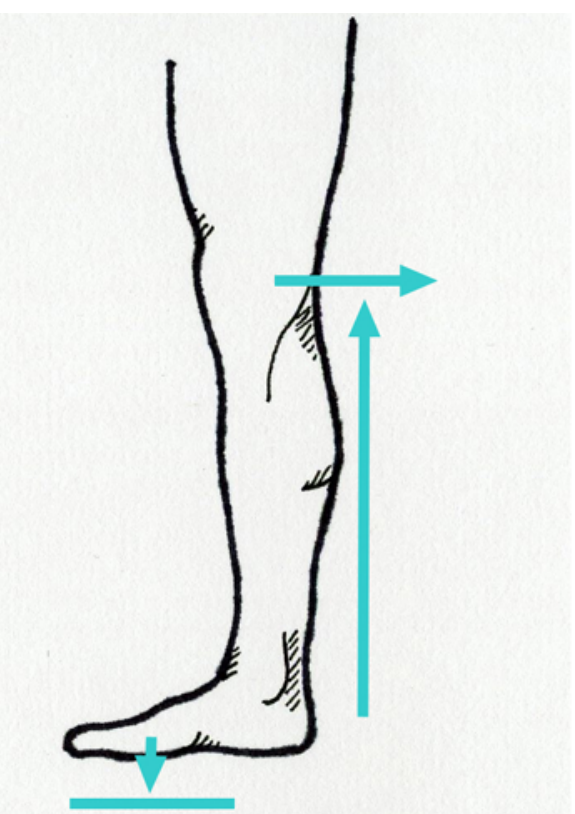

FIG. 11. Complementary rehabilitation through the plantar flexion-knee extension couple: Under normal loading conditions when the foot is planted, the plantar flexors will provide a posteriorly directed force to the knee joint to create an extension moment. Copyright Thomas Tung. Published with permission. Figure is available in color online only.

and soleus muscles provide the most support, whereas in late stance prior to toe off, the soleus and gastrocnemius muscles provide the main support. Thus, activation of the vasti muscles will also contract the plantar flexors during midstance and the transition to late stance. ${ }^{1}$ These muscle groups are also complementary through the plantar flexion-knee extension couple, which plays an important role during normal ambulation (Fig. 11).,13 The quadriceps muscles control the first phase of knee extension in response to loading and become relatively insufficient toward full extension. The second phase, which leads to maximal knee extension, is provided by the plantar flexors. Under normal loading conditions when the foot is planted, the plantar flexors will provide a posteriorly directed force to the knee joint to create an extension moment. We believe this provides a potential explanation for why reconstruction of even a small amount of plantar flexion such as that seen in our patients produced a more general and noticeable improvement in gait kinematics and allowed them to do things they were previously unable to do, such as run.

\section{Conclusions}

Early clinical experience and anatomical study illustrated the feasibility of lower-extremity nerve transfers to restore tibial nerve function in proximal injuries without long nerve grafts. Further clinical experience and analysis will allow refinement of the technique, particularly in ensuring that synergy and nerve fiber count are maximized to optimize recipient recovery without degrading donor function.

\section{Acknowledgments}

We gratefully acknowledge Dan Hunter for his expertise in the histomorphometric analysis of cadaver specimens.

\section{References}

1. Anderson FC, Pandy MG: Individual muscle contributions to support in normal walking. Gait Posture 17:159-169, 2003

2. Bodily KD, Spinner RJ, Bishop AT: Restoration of motor function of the deep fibular (peroneal) nerve by direct nerve transfer of branches from the tibial nerve: an anatomical study. Clin Anat 17:201-205, 2004

3. Brunner R, Rutz E: Biomechanics and muscle function during gait. J Child Orthop 7:367-371, 2013

4. Burks SS, Levi DJ, Hayes S, Levi AD: Challenges in sciatic nerve repair: anatomical considerations. J Neurosurg 121:210-218, 2014

5. Clawson DK, Seddon HJ: The results of repair of the sciatic nerve. J Bone Joint Surg Br 42:205-212, 1960

6. Farber SJ, Glaus SW, Moore AM, Hunter DA, Mackinnon SE, Johnson PJ: Supercharge nerve transfer to enhance motor recovery: a laboratory study. J Hand Surg Am 38:466-477, 2013

7. Flores LP: Proximal motor branches from the tibial nerve as direct donors to restore function of the deep fibular nerve for treatment of high sciatic nerve injuries: a cadaveric feasibility study. Neurosurgery 65 (6 Suppl):218-225, 2009

8. Giuffre JL, Bishop AT, Spinner RJ, Levy BA, Shin AY: Partial tibial nerve transfer to the tibialis anterior motor branch to treat peroneal nerve injury after knee trauma. Clin Orthop Relat Res 470:779-790, 2012

9. Giuffre JL, Bishop AT, Spinner RJ, Shin AY: Surgical technique of a partial tibial nerve transfer to the tibialis anterior motor branch for the treatment of peroneal nerve injury. Ann Plast Surg 69:48-53, 2012

10. Hunter DA, Moradzadeh A, Whitlock EL, Brenner MJ, Myckatyn TM, Wei CH, et al: Binary imaging analysis for comprehensive quantitative histomorphometry of peripheral nerve. J Neurosci Methods 166:116-124, 2007

11. Kahn LC, Moore AM: Donor activation focused rehabilitation approach: Maximizing outcomes after nerve transfers. Hand Clin 32:263-277, 2016

12. Kim DH, Murovic JA, Tiel R, Kline DG: Management and outcomes in 353 surgically treated sciatic nerve lesions. J Neurosurg 101:8-17, 2004

13. Kimmel SA, Schwartz MH: A baseline of dynamic muscle function during gait. Gait Posture 23:211-221, 2006

14. Kline DG, Kim D, Midha R, Harsh C, Tiel R: Management and results of sciatic nerve injuries: a 24-year experience. $\mathbf{J}$ Neurosurg 89:13-23, 1998

15. Korompilias AV, Payatakes AH, Beris AE, Vekris MD, Afendras GD, Soucacos PN: Sciatic and peroneal nerve injuries. Microsurgery 26:288-294, 2006

16. Koshima I, Nanba Y, Tsutsui T, Takahashi Y: Deep peroneal nerve transfer for established plantar sensory loss. J Reconstr Microsurg 19:451-454, 2003

17. Millesi H: Lower extremity nerve lesions, in Terzis JK (ed): Microreconstruction of Nerve Injuries. Philadelphia: W.B. Saunders, 1987, pp 239-252

18. Moore AM, Tung TH: Brachial plexus injuries, in Mackinnon SE (ed): Nerve Surgery. New York: Thieme, 2014, pp 391467

19. Murovic JA: Lower-extremity peripheral nerve injuries: a Louisiana State University Health Sciences Center literature review with comparison of the operative outcomes of 806 Louisiana State University Health Sciences Center sciatic, common peroneal, and tibial nerve lesions. Neurosurgery 65 (4 Suppl):A18-A23, 2009 
20. Nath RK, Lyons AB, Paizi M: Successful management of foot drop by nerve transfers to the deep peroneal nerve. $\mathbf{J}$ Reconstr Microsurg 24:419-427, 2008

21. Roganović Z, Pavlićević G, Petković S: Missile-induced complete lesions of the tibial nerve and tibial division of the sciatic nerve: results of 119 repairs. J Neurosurg 103:622629,2005

22. Samardzić MM, Rasulić LG, Vucković CD: Missile injuries of the sciatic nerve. Injury 30:15-20, 1999

23. Spiliopoulos K, Williams Z: Femoral branch to obturator nerve transfer for restoration of thigh adduction following iatrogenic injury. J Neurosurg 114:1529-1533, 2011

24. Sunderland IR, Brenner MJ, Singham J, Rickman SR, Hunter DA, Mackinnon SE: Effect of tension on nerve regeneration in rat sciatic nerve transection model. Ann Plast Surg 53:382-387, 2004

25. Taha A, Taha J: Results of suture of the sciatic nerve after missile injury. J Trauma 45:340-344, 1998

26. Tung TH, Chao A, Moore AM: Obturator nerve transfer for femoral nerve reconstruction: anatomic study and clinical application. Plast Reconstr Surg 130:1066-1074, 2012

27. Tung TH, Mackinnon SE: Brachial plexus injuries. Clin Plast Surg 30:269-287, 2003

28. Tung TH, Mackinnon SE: Nerve transfers: indications, techniques, and outcomes. J Hand Surg Am 35:332-341, 2010

29. Urso-Baiarda F, Grobbelaar A: Use of the interposed nerve graft to reduce differences in functional muscle transfer outcome arising from variability in motor input. J Plast Reconstr Aesthet Surg 64:432-438, 2011

30. Winter DA, Yack HJ: EMG profiles during normal human walking: stride-to-stride and inter-subject variability. Electroencephalogr Clin Neurophysiol 67:402-411, 1987

31. Wootten ME, Kadaba MP, Cochran GVB: Dynamic electromyography. II. Normal patterns during gait. J Orthop Res 8:259-265, 1990

32. Yin G, Chen H, Hou C, Xiao J, Lin H: Obturator nerve transfer to the branch of the tibial nerve innervating the gastrocnemius muscle for the treatment of sacral plexus nerve injury. Neurosurgery 78:546-551, 2016

\section{Disclosures}

The authors report no conflict of interest concerning the materials or methods used in this study or the findings specified in this paper.

\section{Author Contributions}

Conception and design: Tung, Moore. Acquisition of data: Tung, Moore, Krauss, Franco. Analysis and interpretation of data: Tung, Moore, Krauss, Parikh. Drafting the article: Moore, Krauss, Parikh. Critically revising the article: Tung, Moore. Reviewed submitted version of manuscript: Tung, Moore. Approved the final version of the manuscript on behalf of all authors: Tung. Statistical analysis: Tung, Moore, Krauss, Parikh. Administrative/technical/ material support: Tung, Moore. Study supervision: Tung, Moore.

\section{Supplemental Information \\ Videos}

Video 1. https://vimeo.com/224946985.

Video 2. https://vimeo.com/224947354.

Video 3. https://vimeo.com/224947469.

Video 4. https://vimeo.com/224947581.

Video 5. https://vimeo.com/224947210.

Video 6. https://vimeo.com/224947693.

Video 7. https://vimeo.com/224947814.

\section{Previous Presentations}

This paper has been presented as a poster presentation at the 2015 Annual Meeting of the American Society for Peripheral Nerve held in Nassau, Bahamas, on January 23-25, 2015, and at the Plastic Surgery Research Council 61st Annual Meeting 2016 held in New York, New York, on May 19-22, 2016.

\section{Correspondence}

Thomas H. Tung, Division of Plastic and Reconstructive Surgery, Washington University School of Medicine, 660 South Euclid Ave., Campus Box 8238, St. Louis, MO 63110.email: tungt@ wustl.edu. 